
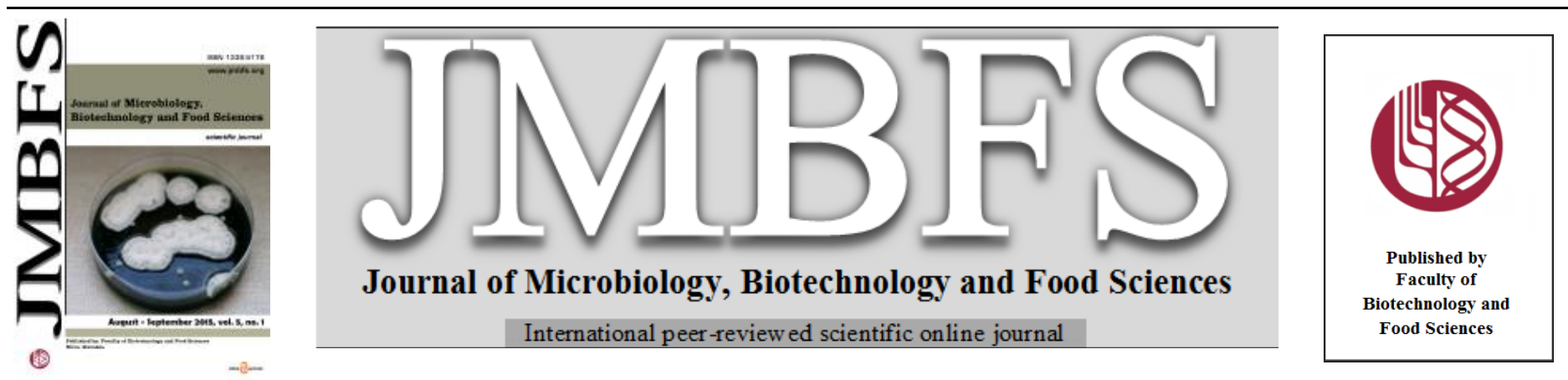

\title{
KAPPAPHYCUS ALVAREZII : ITS ANTIOXIDANT POTENTIAL AND USE IN BIOACTIVE PACKAGING FILMS
}

\author{
Sweetie R. Kanatt* ${ }^{1}$, Priyanka Lahare ${ }^{2}$, S. P. Chawla ${ }^{1}$ \& Arun Sharma ${ }^{1}$ \\ Address(es): Dr. Sweetie R. Kanatt \\ ${ }^{1}$ Food Technology Division, Bhabha Atomic Research Centre, Trombay, Mumbai, INDIA - 400 085, Tel.: +91-22-25593296/25595374. \\ ${ }^{2}$ KET'S V.G.Vaze College, Mulund (E), Mumbai.
}

*Corresponding author: srkanatt@ barc.gov.in

doi: 10.15414/jmbfs.2015.5.1.1-6

\section{ARTICLE INFO}

Received 2. 9.2014

Revised 17. 4. 2015

Accepted 24. 4. 2015

Published 1. 8. 2015

Regular article

OPEN ACCESS

\begin{abstract}
The bioactive properties of Kappaphycus alvarezii, red seaweed, were investigated. Water was the best solvent for extraction of seaweed and the aqueous seaweed extract (SWE) showed the highest yield, phenolic and flavanoid content. It exhibited good antioxidant activity as measured by DPPH assay, reducing power, iron chelating activity and $\beta$-carotene bleaching assay. SWE also showed antimicrobial activity against $S$ aureus and $B$ cereus. Composite films prepared using SWE and poly vinyl alcohol (PVA) showed excellent barrier properties against UV light. The films had good mechanical characteristics measured in terms of tensile strength, \% elongation and puncture strength. SWE containing PVA films had low oxygen transfer, good antioxidant and antibacterial activity. Results demonstrated that SWE has good antioxidant and antibacterial activity and it could be used to prepare bioactive food packaging films useful for the food industry.
\end{abstract}

\section{INTRODUCTION}

Seaweeds are marine algae that are rich source of proteins, $\omega 3$ and $\omega 6$ polyunsaturated fatty acids, vitamins, minerals and fiber (Chapman, 1970). In Japan, China and Korea seaweeds are traditionally consumed as foodor used as fertilizer and animal feed additives. Based on pigmentation they are broadly grouped into three different classes; green (Chlorophyceae), brown (Phaeophyceae) and red (Rhodophyceae) algae. Kappaphycus alvarezii, is an edible red seaweed found in Malaysia, Kenya, China and India. They are also cultivated in coastal areas as it is one of the most important commercial sources of carrageenan, a family of gel-forming polysaccharide. Kappaphycus spp. have high carrageenan content and diverse industrial applications (Rodrigueza and Montaño, 2007). In food industry they are used as gelling and emulsifying agent. In dairy products carrageenans are used at low concentration to prevent fractionation of milk constituents.. They are also used in pharmaceutical formulations and cosmetics.

Seaweed extracts are a rich source of structurally diverse bioactive compounds and it has a great potential to be used as a naturalbiomaterial. There are some reports that have shown anti-viral (Artan et al., 2008), anti-tumor (Alekseyenko et al., 2007), anti inflammatory, antimicrobial (Cox et al., 2009) and antioxidant (Kumar et al., 2008) activities of different seaweeds.

Packaging of food is essential to ensure its quality from the time of manufacture to the time it is used by the consumer. The most commonly used packaging materials are petrochemical based polymers which are non-biodegradable. Therefore, films from natural polymers have become an ecologically important alternative. Combination of different polymers is an effective method to develop novel material with desired properties. Polyvinyl alcohol (PVA), is a synthetic polymer that is biodegradable and has excellent mechanical properties. Seaweed extract (SWE) has film forming properties due to the carrageenan present and also is rich in bioactive compounds. Thus the main objectives of this study were; (a) to investigate the bioactive properties of SWE (b) to prepare composite films based on PVA and SWE, and (c) to evaluate the functional properties of the films.

\section{MATERIALS AND METHODS}

Chemicals

$\beta$-Carotene, linoleic acid, 1,1-diphenyl-2-picrylhydrazyl (DPPH) and catechin were procured from Sigma Chemical Co. (St. Louis, MO). PVA (molecular weight $1.4 \times 10^{5} \mathrm{Da}$ ), Ferrozine and microbiological media were purchased from HiMedia (Mumbai, India). All other reagents used were of analytical grade and procured from Qualigens Fine Chemicals (Mumbai, India). Dry seaweed powder was gifted by Aquagri Processing Pvt. Ltd.

\section{Bacterial cultures}

Escherichia coli JM109, Pseudomonas fluorescens ost5 (16s rRNA gene sequence submitted to Genbank, Accession no. DQ439976) a laboratory isolate, Staphylococcus aureus ATCC 6538P, Bacillus cereus MTCC 470, were stored in $20 \%$ glycerol $(\mathrm{v} / \mathrm{v})$ at $-20^{\circ} \mathrm{C}$. Before the start of experiment, the cultures were grown on nutrient agar. The isolates were subcultured twice before inoculation.

\section{Preparation of seaweed extracts (SWE)}

Dry seaweed powder $(100 \mathrm{~g})$ was refluxed with distilled water $(1000 \mathrm{ml})$ for $1 \mathrm{~h}$ It was then filtered using cheesecloth and centrifuged at $12,100 \mathrm{x} \mathrm{g}$ for $20 \mathrm{~min}$ The supernatant was concentrated using a rotary evaporator (Buchi Rotavapor, Flawil, Switzerland). The concentrate was then lyophilized to form a powder and stored at $4{ }^{\circ} \mathrm{C}$ until analyzed. Extraction with other solvents namely ethanol, $70 \%$ ethanol and methanol were also carried out in the same way.

\section{Determination of total phenolics and flavonoids}

Total phenolic content of SWE was determined according to the Folin-Ciocalteu procedure (Singleton and Rossi, 1965). The flavonoid content was evaluated according to the colorimetric assay of Kim et al., (2003). For both the assays a calibration curve was prepared with catechin and the results were expressed as catechin equivalents. 


\section{Determination of antioxidant activity}

DPPH assay was performed according to the method of Yamaguchi et al., (1998). Percent DPPH-scavenging activity was calculated. The antioxidan activity coefficient was estimated by thermally induced beta-carotene bleaching assay, as described by Velioglu et al., (1998). The reducing power of appropriately diluted SWE was determined according to the method of Oyaizu (1986). Results were expressed as OD at $700 \mathrm{~nm}$. Iron chelation capacity of SWE was determined as described by Decker and Welch (1990). Results were expressed as percentage iron chelation.

\section{Antibacterial activity of SWE}

The antibacterial activity of SWE was measured against $S$. aureus, B. cereus, Ps. fluroscence and $E$. coli. The test culture was grown overnight in nutrient broth. Appropriately diluted cell pellet was added to tubes containing SWE. Initially (0 h) sample was withdrawn, serial dilutions carried out, plated on plate count agar and counted after incubation at $37^{\circ} \mathrm{C}$ for $24 \mathrm{~h}$. This gave the initial number of the test organism. All the tubes were then incubated for $3 \mathrm{~h}$ at $37{ }^{\circ} \mathrm{C}$, the aliquots were again taken and the surviving population was determined. The antibacterial activity of SWE was assessed by decrease in $\log \mathrm{cfu} / \mathrm{ml}$ of the test culture after incubation for $3 \mathrm{~h}$

\section{Film preparation}

The films were prepared by casting method. PVA solution $(5 \% \mathrm{w} / \mathrm{v})$ and SWE solution $(1 \% \mathrm{w} / \mathrm{v})$ was first prepared separately. Three types of films were prepared using these solutions. First type of films was prepared with only PVA solution. The second type of films was prepared from blend containing $90 \%$ PVA $(5 \% \mathrm{w} / \mathrm{v})$ and $10 \% \mathrm{SWE}(1 \% \mathrm{w} / \mathrm{v})$. Glycerol $(0.1 \% \mathrm{v} / \mathrm{v}$ of film forming solution was added to blend containing $90 \%$ PVA (5\% w/v) and $10 \% \mathrm{SWE}(1 \% \mathrm{w} / \mathrm{v})$ and used to prepare the third type of film. Effective concentration of SWE in the second and third type of film was $0.06 \mathrm{ml} / \mathrm{cm}^{2}$. All the three film forming solutions were stirred on a magnetic stirrer $(200 \mathrm{rpm})$ at room temperature for 1 hour, followed by homogenisation (Polytron PT 2100, Kinematica, Switzerland) The film forming solutions were then degassed (Equivac-VO2 Vacuum pump, Medica Instruments, India) to remove the air bubbles. The films were then cas by pouring the film forming solution $(150 \mathrm{ml})$ onto teflon plates $(15 \mathrm{~cm} \times 15 \mathrm{~cm})$ and dried at $50{ }^{\circ} \mathrm{C}$ in a ventilated oven at $50 \%$ relative humidity $(\mathrm{RH})$ for $18-20 \mathrm{~h}$ to obtain films of uniform thickness. Film characteristics were determined after all sample films were preconditioned in a constant temperature humidity chamber (Model FX 1077, Jeiotech Co., Ltd., India) set at $23^{\circ} \mathrm{C}$ with $50 \% \mathrm{RH}$ for $24 \mathrm{~h}$.

\section{Film thickness}

Film thickness was measured using a hand-held micrometer (Mitotuyo No. 7327 Tokyo, Japan). Measurements were taken at six different locations of each film sample and the average film thickness was calculated.

\section{Optical properties}

The ultraviolet and visible light barrier properties of the films were measured using a UV/vis spectrophotometer (Model UV-1601, Shimadzu Co., Kyoto, Japan). The results have been expressed as percentage transmittance. The transparency at $600 \mathrm{~nm}$ (T600) was obtained using the following equation (Han and Floros, 1997).

$\mathrm{T} 600=-\log \% \mathrm{~T} / \mathrm{b}$

Where, $\% \mathrm{~T}$ is percentage transmittance and $\mathrm{b}$ is the film thickness $(\mathrm{mm})$ According to the equation, high transparency indicates that the film is more opaque.

\section{Mechanical properties of films}

Tensile strength (TS), percentage elongation at break $(\% \mathrm{E})$ and puncture strength were measured using Texture Analyzer TA-HD plus (Stable Micro Systems, Surrey, UK) in accordance with ASTM D882-91 method (ASTM, 1991). For both, tensile or puncture tests, each reported value corresponded to at least five determinations.

\section{Water vapour transmission rate (WVTR) and oxygen permeability (OP)}

WVTR tests were carried out using an automatic water vapour permeability testing machine L80-5000 (PBI Dansensor, Denmark) at $37^{\circ} \mathrm{C}$ and 10/15\% RH. $\mathrm{OP}$ of the film was estimated with automated oxygen permeability testing machine OPT-5000 (PBI Dansensor, Denmark) at $23^{\circ} \mathrm{C}$ and $0 \%$ RH. WVTR and $\mathrm{OP}$ of each sample were averaged from three separate tests.

\section{Water solubility of films}

Film's water solubility was measured by method of Stuchell and Krochta (1994). Total water soluble matter was calculated as follows

$\mathrm{W}_{\mathrm{s}}(\%)=\left(\mathrm{w}_{0}-\mathrm{w}_{\mathrm{d}} / \mathrm{w}_{0}\right) \times 100$

where $\mathrm{W}_{\mathrm{s}}$ is the water solubility, $\mathrm{w}_{0}$ is the weight before absorption, $\mathrm{w}_{\mathrm{d}}$ is the dry weight of the swelled film

\section{Antioxidant and antibacterial activity of films}

Films $\left(5 \mathrm{~cm}^{2}\right)$ were placed in conical flasks containing $10 \mathrm{ml}$ of distilled water. These flasks were then continuously shaken in orbital shaker $(100 \mathrm{rpm})$. Three sets of each film were taken. The antioxidant activity of the films was monitored by taking aliquots of the supernatant obtained from each flask after 3 hours and analyzed for DPPH radical scavenging activity. Antibacterial activity of film samples (diameter of $1.5 \mathrm{~cm}$ ) was carried out by aseptically placing the films on PCA plates streaked with the test organisms. Zone of inhibition was measured after incubation of the plates at $37^{\circ} \mathrm{C}$ for 24 hours.

\section{Statistical analysis}

All experiments were carried out in triplicate and the average values with standard errors were reported. Analysis of variance was conducted and differences between variables were tested for significance by one-way ANOVA (Tukey). A statistical difference at $p<0.05$ was considered to be significant.

\section{RESULTS AND DISCUSSION}

\section{Effect of solvent on the yield of seaweed extract}

In order to determine the best solvent for extraction of seaweed, different solvents such as water, ethanol, aqueous ethanol and methanol were tested. The highest yield was obtained when seaweed was extracted with water $(67.49 \%)$ while the percentage yield of seaweed extract using aqueous ethanol (18.4\%), methanol $(10.27 \%)$ and ethanol $(1.36 \%)$ was relatively very low (Table 1$)$. This is in accordance with a study by Farvin and Jacobsen (2013), who reported that water extracts showed higher yield $(14.1 \%$ to $51.3 \%)$ when compared to ethanolic extracts $(2.7 \%$ to $28.4 \%)$ for 16 seaweed species consisting of brown, green and red seaweeds collected from the coastal areas of Denmark. However, Airanthi et al., (2011) have reported that in case of Japanese edible brown seaweeds, methanol was the most effective solvent for extraction. Polar solvents are effective in extracting sugar attached polyphenols, tannins, saponins, glycosides and organic acids.

\section{Total phenolic and flavonoid content}

Phenolics widely distributed in the plant kingdom, are the most abundant secondary metabolites of plants, mainly responsible for the antioxidant activity. The total phenolic and flavanoid content of SWE using various solvents is shown in Table 1. The phenolic content of aqueous seaweed extract (SWE) was $6.56 \mathrm{mg}$ in terms of catechin equivalent/g of the sample. Seaweed extracted with other solvents had significantly $(p<0.05)$ lower phenolic content. Similar phenolic concentrations were observed by Ganesan et al., (2008) in methanolic extracts of red seaweed which ranged from $1.5 \mathrm{mg}$ gallic acid equivalent/g (Euchema kappaphycus) to $4.1 \mathrm{mg} / \mathrm{g}$ (Gracilaria edulis). Flavanoid content of SWE was low $(0.19 \mathrm{mg}$ in terms of catechin equivalent $/ \mathrm{g})$ compared to the total phenolic content. Lalopua et al., (2011) reported total flavonoid of $0.00187 \mathrm{mg}$ expressed in quercetin equivalent/g of dry extract from $K$. alvarezii (doty). Among various solvents used for extraction of seaweed, aqueous extract showed the highest total phenolic and flavonoid content. Santoso, Yoshie, and Suzuki (2002) identified flavonoid compounds such as catechin, flavonols and flavonol glycosides from extracts of red algae. Phenolic compounds play a significant role in the cell's defence against biotic and abiotic stresses. In macroalgae total phenolic content vary significantly depending on the variety of seaweed, exposure to sunlight, climate and location on the shore (Cox et al., 2010).

\section{Antioxidant assays}

Natural compounds have antioxidant activity due to several mechanisms such as scavenging of free radicals, chelation of metal ions and quenching of singlet oxygen. Hence multiple assays are necessary to ensure better comparison of the results, covering wider range of possible applications. Antioxidant potential of crude extract from seaweed was therefore investigated using various in vitro assays.

\section{DPPH radical scavenging activity}

The DPPH radical scavenging assay is based on the reduction of DPPH, a stable free radical which due to its odd electron gives a maximum absorption at $517 \mathrm{~nm}$ (purple colour). Free radical scavenging ability of SWE was evaluated with the 
change of absorbance caused by the reduction of DPPH radical and is shown in Fig.1. Scavenging activity increased with the increase in concentration of SWE. Maximum DPPH radical scavenging activity was seen in aqueous SWE which had an $\mathrm{IC}_{50}$ of $5.03 \mathrm{mg} / \mathrm{ml}$. Methanolic extract of the seaweed had the lowest DPPH radical scavenging activity. Siriwardhana et al., (2003) have also reported higher DPPH scavenging activities for water extracts of Hizikia fusiformis (brown algae) than found in ethanol, chloroform and ethyl acetate extracts, although these extracts also had strong scavenging activities over $50 \%$. The interaction of a potential antioxidant with DPPH depends on its structural conformation. The number of DPPH molecules reduced correlates with the number of available hydroxyl groups. In the present study we found a positive correlation $\left(r^{2}=0.978, p<0.05\right)$ between DPPH-scavenging activity and tota phenolic content in case of aqueous SWE. A direct correlation between the tota phenolic content and DPPH radical-scavenging has also been reported by other researchers (Wangensteen et al., 2004; Siriwardhana et al., 2003).

\section{Iron chelation activity}

Metal ion chelating capacity plays a significant role in antioxidant mechanism since it reduces the concentration of the catalyzing transition metal in lipid peroxidation. The ability of SWE to compete with ferrozine for binding of ferrous ion and thereby avoiding the formation of the colored complex (absorbance peak at 562nm) was measured. Fig. 1. presents the iron chelating activity of various SWE. Aqueous SWE had the best iron chelation activity $\left(\mathrm{IC}_{50}\right.$ $4.82 \mathrm{mg} / \mathrm{ml}$ ) while the least activity was seen in the methanolic SWE. Polarity of the extracting solvent alters its efficacy to extract a specific group of antioxidant compounds and that influence the antioxidant properties of the extracts (Zhou and Yu, 2004). Farvin and Jacobson (2013) also reported that water extracts of seaweeds collected from the coastal areas of Denmark showed significantly higher ferrous ion chelating activity than ethanolic extracts. Algal dietary fibres such as carrageenan, have metal binding capacities.

\section{$\beta$-carotene bleaching assay}

In this assay, $\beta$-carotene is oxidized by the free radicals produced from the oxidized linoleic acid. In the absence of an antioxidant, the $\beta$-carotene molecule loses its chromophore and undergoes, rapid discoloration, which can be monitored spectophotometrically. However in the presence of an antioxidant $\beta$ carotene retains its original yellowish-orange color by scavenging the free radicals formed in the system. This assay closely stimulate a real food system compared to DPPH assay Fig. 2. shows antioxidant activity coefficient (AAC) of SWE which increased with the increase in concentration of extract. Among the various extracts aqueous extract of SWE had the highest AAC of 694.3 at a concentration of $5 \mathrm{mg} / \mathrm{ml}$. Lowest AAC values (384) were obtained in seaweed extract that was extracted with absolute ethanol. Similar results were reported by Ismail and Hong (2002) who showed that in Kumbu (Laminaria sp.), a commercial seaweed available in Malaysian supermarkets, its water extract exhibited antioxidant activity that was 17 times higher than that of ethanolic extract.

\section{Reducing power assay}

The antioxidant activity of natural extracts often correlates with its reductive activity. The presence of reductones in the extract causes the reduction of the $\mathrm{Fe}^{3+} /$ ferricynide complex to the ferrous form which is monitored by measuring the formation of Perl's Prussian blue at a wavelength of $700 \mathrm{~nm}$. Reductones inhibit lipid peroxidation by donating a hydrogen atom and thereby terminating free radical chain reaction. Fig. 2. depicts the reducing power of the different SWEs. Maximum reducing power was observed in seaweed extracted with water. At a concentration of $5 \mathrm{mg} / \mathrm{ml}$ the reducing power of aqueous SWE was three times more as compared to methanolic extract of seaweed which had the least reducing capacity, indicating that more hydrophilic compounds present in the water extracts affect their reducing capacities.

\section{Antimicrobial activity of aqueous seaweed extract}

As aqueous SWE had maximum antioxidant activity only this extract was examined for antimicrobial activity. The results of the antibacterial assay (Fig. 3.) showed that Gram positive $S$. aureus and B. Cereus was sensitive as their growth was inhibited by SWE. The antimicrobial activity of SWE was more evident in case of $S$. aureus, as there was more than two log cycle reduction in growth when $0.5 \%$ aqueous SWE was used. In case of $B$. Cereus, one log cycle reduction in growth was obtained by $0.5 \%$ SWE. No antibacterial activity was observed against gram negative E. coli and Ps fluroscence. Phenolic compounds present in aqueous extract of seaweed may be responsible for antimicrobial activity. Liu et al., (2011) isolated four bromophenols from marine red algae, $R$. confervoides, which showed powerful antimicrobial activity against $S$. aureus. Rhimou et al. (2010) studied the antibacterial activity of extracts from 26 species of red algae against three Gram-positive and two Gram-negative bacteria and found that $S$ aureus was the most susceptible microorganism.

\section{Film properties}

\section{Appearance and thickness of films}

All the films could be easily peeled from the teflon plates and were homogeneous and flexible. Visually, PVA films blended with SWE had a slightly yellow appearance. The average thickness of films containing only PVA $(0.225 \pm 0.007$ $\mathrm{mm})$ was more than films in which SWE $(0.200 \pm 0.001 \mathrm{~mm})$ was added. No significant change in film thickness was found by the addition of glycerol (Table 2). Rattaya et al., (2009) have reported a thickness of $0.031 \mathrm{~mm}$ for fish skin gelatin films containing brown seaweed ( $T$. ornate). The thickness of the film generally affects mechanical properties, water vapour/oxygen permeability, light transmission, and transparency of films.

\section{Light transmission and film transparency}

The films were scanned in a UV-visible spectrophotometer between 200 and 800 $\mathrm{nm}$ and results are shown in Fig. 4. In the UV region, films made with only PVA exhibited high percentage transmission, while PVA films containing SWE had low percent transmittance. SWE contains phenolic compounds which absorb in the UV region and therefore SWE containing films have excellent barrier properties against UV light, which could induce lipid oxidation in the food system. Improved light barrier properties were reported when murta extract or ginseng extract was added to gelatine or alginate films respectively (Norajit et al., 2010; Gómez-Estaca et al., 2009). In the visible range, \% $\mathrm{T}$ ranged from $29 \%$ to $38 \%$ for only PVA containing films while in films containing SWE it ranged from $16 \%$ to $41 \%$ respectively (Fig. 4.). The incorporation of SWE resulted in an increase in film transparency value (Table 2). The higher transparency value indicates that the film is more opaque and this could be due to the darker color caused by addition of SWE. In contrast Rattaya et al. (2009) did not find any difference in the transparency of gelatin films incorporated with and without seaweed extract.

\section{Mechanical properties}

Mechanical properties of biopolymer films are extremely important and depend on the nature of the polymers, solvent system and final compositions.

Tensile strength and \% elongation

Tensile strength and \% elongation of studied films are shown in Table 2. Films made with only PVA had the highest tensile strength. Addition of SWE reduced the tensile strength by $18.24 \%$. The reduction in the mechanical properties as affected by additives has been previously reported for hydrocolloid-based films (Gontard et al., 1993). There was further reduction in tensile strength on addition of glycerol. Films prepared with PVA, SWE and glycerol had a tensile strength of $23.95 \mathrm{MPa}$ as compared to $27.84 \mathrm{MPa}$ for films with only PVA and SWE. Percentage elongation at break of SWE containing PVA films was higher as compared to only PVA films. Similar results were reported by Rattaya et al., (2009) who found that fish skin gelatin films incorporated with $6 \%$ seaweed (Turbinaria ornata) extract exhibited higher elongation at break than the control film. On addition of glycerol, the percentage elongation of PVA-SWE films increased from 85.05 to 129.7 . Glycerol reduces the cohesive intermolecular forces along the polymer chains due to which they can move more freely relative to one another and the stiffness of the polymer is reduced and it has better flexibility.

\section{Puncture strength}

Puncture test is a measure of the resistance of the film to be perforated. The puncture strength of film made with only PVA was $10.63 \mathrm{~N}$ while film containing PVA and SWE had a higher puncture strength of $13.85 \mathrm{~N}$ (Table 2). Similar results were reported by Sivarooban et al., (2008), who found that incorporation of grape seed extract to soy protein films significantly increased the puncture strength (from 2.5 to $5.3 \mathrm{~N}$ ). The different composition of polyphenols present in the natural extracts could have possibly increased the number of intermolecular cross-links in the film-forming solution. Addition of glycerol to the SWE-PVA film significantly $(p<0.05)$ reduced its puncture strength $(8.49 \mathrm{~N})$ These results are comparable to results reported by Gontard et al. (1993), who showed that puncture strength, decreased as glycerol concentration increased in wheat gluten films.

\section{Water vapour and oxygen permeability}

The determination of the barrier properties of water vapour and oxygen in the packaging film is crucial to estimate the shelf-life of food. Oxygen promotes oxidation of food resulting in several undesirable changes such as deterioration of odor, color, flavor and nutrients present in food. Thus, developing films with adequate oxygen barrier can help improve food quality and extend food shelf-life. Table 2 shows that film with only PVA had the highest oxygen permeability $\left(49.0 \mathrm{~cm}^{3} / \mathrm{m}^{2} /\right.$ day). Addition of SWE lowered the permeability to 3.37 $\mathrm{cm}^{3} / \mathrm{m}^{2} /$ day. Generally, hydrophilic biopolymer films show good oxygen barrier 
property. Addition of glycerol made the film negligibly permeable to oxygen $\left(0.65 \mathrm{~cm}^{3} / \mathrm{m}^{2} /\right.$ day $)$. For non-polar oxygen molecule, the addition of glycerol might fill in the gap between the macromolecule, hindering the permeation of oxygen. Similar results were also reported by Jin et al., (2012) who observed that cellulose films prepared without being treated by glycerol had the highest oxygen permeability, and that oxygen permeability decreased slowly with increasing concentration of glycerol. Another important function of packaging material is to maintain low water vapour transmission rate (WVTR) by preventing moisture transfer between the surrounding atmosphere and food. High WVTR can accelerate the rate of several detrimental reactions in food, enhance microbia growth and cause textural changes thus resulting in decreased shelf life and quality of food. Films made with only PVA had very high WVTR (Table 2). Addition of SWE did not result in any significant reduction in the WVTR. The lowest WVTR was seen in PVA-SWE films containing glycerol. Srinivasa et al., (2007) also reported that incorporation of glycerol in chitosan films decreased the WVTR of films. This result was attributed to the presence of pores within the film without plasticizer, resulting in an increase in WVTR of non plasticized films.

\section{Moisture content and water solubility of films}

The moisture content of films is shown in Table 2. There was no significant change in the moisture content of PVA films on addition of SWE. However, the moisture content increased by $9 \%$ on addition of glycerol $(0.1 \% \mathrm{v} / \mathrm{v}$ of film forming solution). Other studies also reported that the moisture content of carbohydrate based films increased with addition of plasticizer (Ghasemlou et al., 2011). This could be attributed to the water holding capacity of glycerol. The water solubility of edible films is also an important feature when choosing a film for specific applications. Films having high water solubility have the disadvantage of not being able to protect food from moisture but these films will be good for applications were it is used as an edible wrap. It can be seen from Table 2 that films prepared with only PVA had the highest water solubility (94.69\%) while, PVA films containing SWE had lower (80.63\%) water solubility. Similar results were observed by Nunez-Flores et al., (2012) who found that addition of lignosulfonate to gelatine films produced a significant decreased in the water solubility. However, plasticised PVA-SWE films had higher water solubility $(88.51 \%)$ and this may be due to the hydrophilic nature of glycerol.

\section{Antimicrobial and antioxidant activity of films}

Incorporating films with antioxidants/antimicrobials and thereby developing active packaging material is a promising technique for extending food product shelf life. DPPH scavenging assay was used to indicate antioxidant activity of the film. As can be seen from Table 2 only PVA films did not show any antioxidant activity. However, incorporating SWE significantly $(p<0.05)$ enhanced DPPH radical scavenging activity of the films. When glycerol was added to PVA-SWE films the radical scavenging activity reduced by $54 \%$ indicating a decrease in antioxidant activity of these films. SWE also retained its antimicrobial activity when incorporated into PVA films. Good zone of inhibition (Table 2) was seen in PVA-SWE films against growth of both $S$. aureus and B. cereus. There was no significant effect of the plasticiser on the antimicrobial activity of the films.

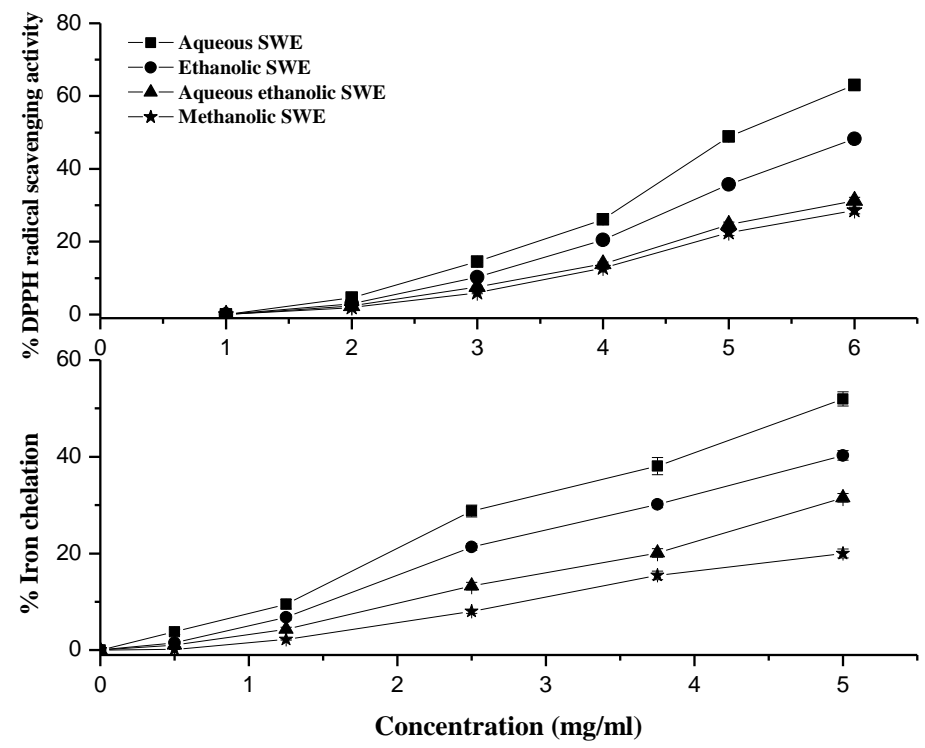

Figure 1 DPPH radical scavenging activity and iron chelation activity of SWE. Results are mean of three independent experiments

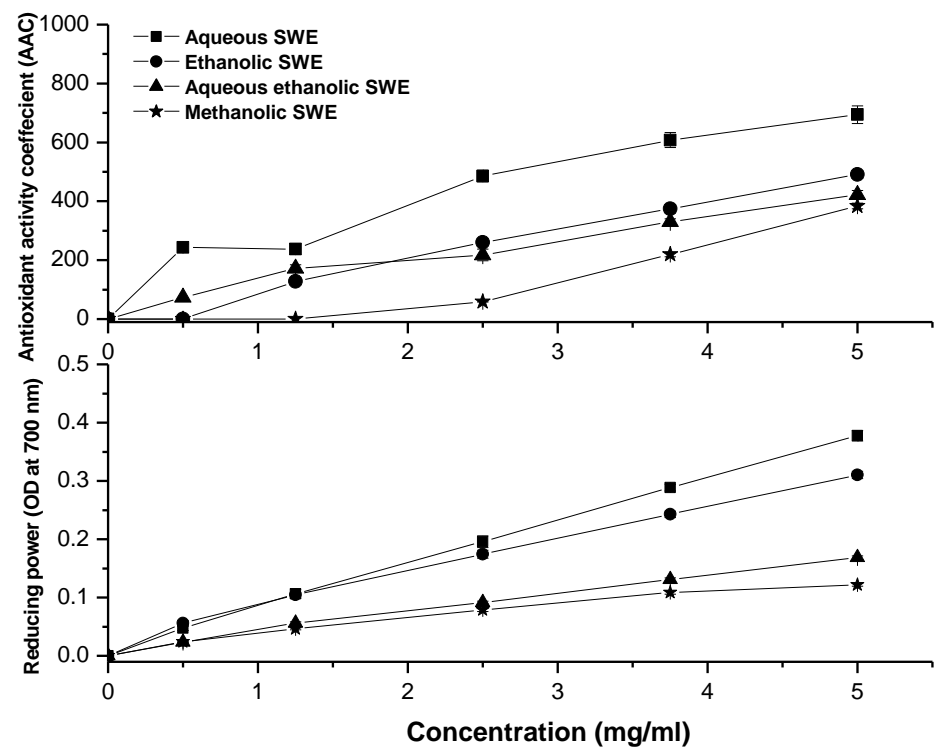

Figure 2 Beta carotene bleaching assay and reducing power of SWE. Results are mean of three independent experiments

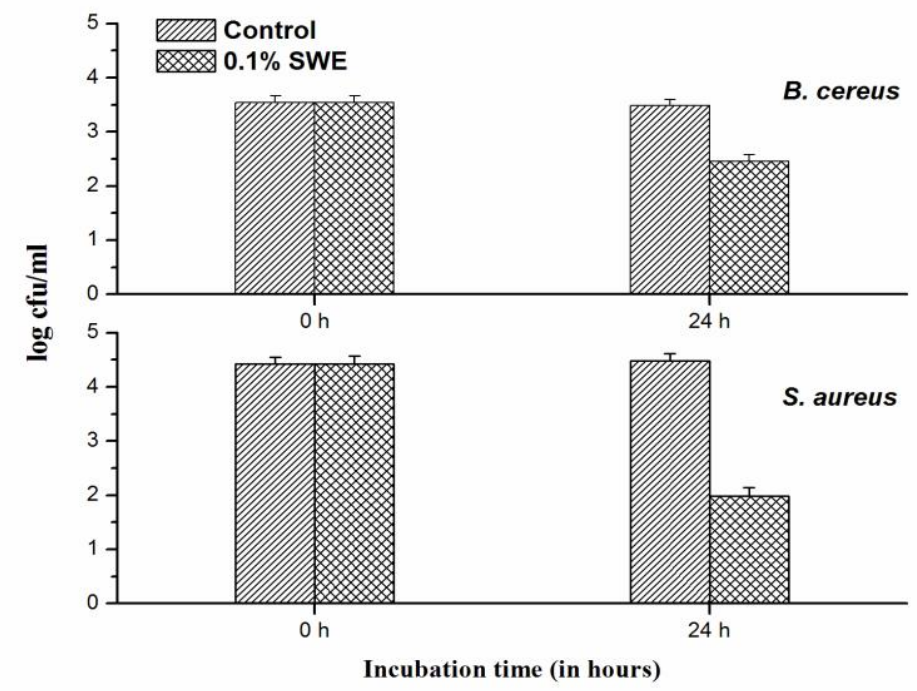

Figure 3 Antibacterial activity of SWE. Results are mean of three independent experiments 


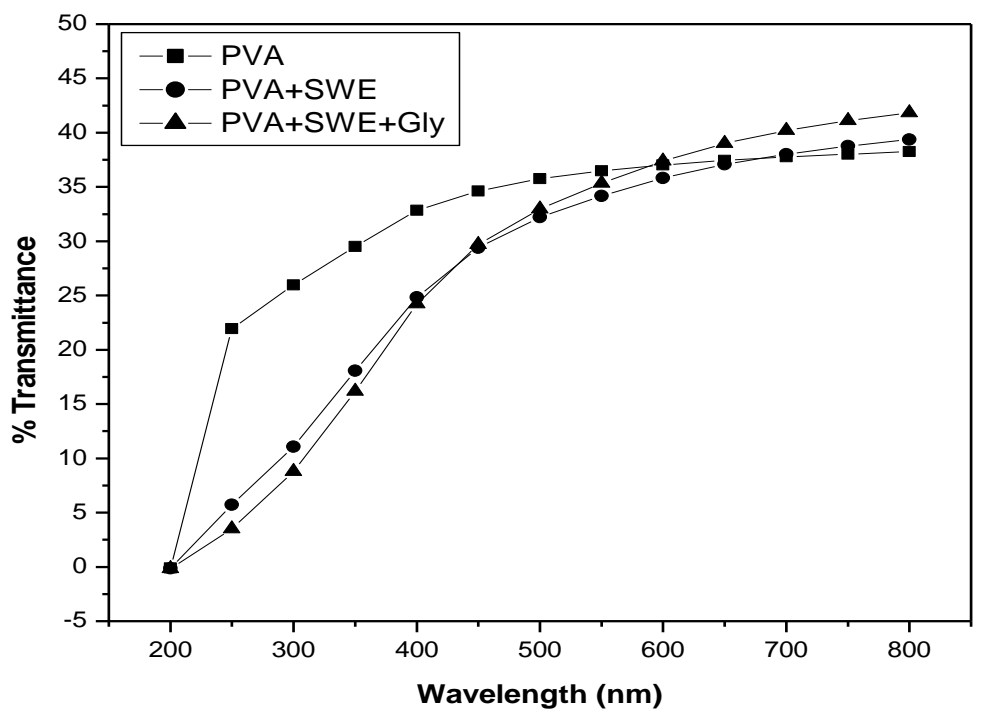

Figure 4 Transmittance of PVA films as affected by the addition of SWE and glycerol

Table 1 Total phenolic and flavanoid content of seaweed extracted using various solvents

\begin{tabular}{|c|c|c|c|c|}
\hline & Water $^{\# *}$ & $\begin{array}{l}\text { Absolute } \\
\text { ethanol }\end{array}$ & $\begin{array}{l}\text { Aqueous } \\
\text { ethanol }\end{array}$ & Methanol \\
\hline Yield (\%) & $67.49 \pm 1.12^{\mathrm{a}}$ & $1.36 \pm 0.22^{\mathrm{d}}$ & $18.4 \pm 0.85^{\mathrm{b}}$ & $10.27 \pm 0.54^{\mathrm{c}}$ \\
\hline $\begin{array}{l}\text { Total phenolics } \\
\text { (mg catechin eq/g) }\end{array}$ & $6.56 \pm 0.34^{\mathrm{a}}$ & $2.72 \pm 0.25^{\mathrm{d}}$ & $4.91 \pm 0.17^{\mathrm{b}}$ & $3.96 \pm 0.10^{c}$ \\
\hline $\begin{array}{l}\text { Total flavanoids } \\
\text { (mg catechin eq/g) }\end{array}$ & $0.19 \pm 0.06^{\mathrm{a}}$ & $0.13 \pm 0.01^{\mathrm{b}}$ & $0.12 \pm 0.01^{\mathrm{b}}$ & $0.03 \pm 0.01^{\mathrm{c}}$ \\
\hline
\end{tabular}

Table 2 Physical, mechanical and functional properties of films

\begin{tabular}{|c|c|c|c|}
\hline & PVA film $^{\# *}$ & PVA+SWE film & PVA+SWE+Gly film \\
\hline Film thickness (mm) & $0.225 \pm 0.007^{\mathrm{a}}$ & $0.200 \pm 0.001^{\mathrm{b}}$ & $0.200 \pm 0.001^{\mathrm{b}}$ \\
\hline Transparency & $6.97 \pm 0.01^{\mathrm{b}}$ & $7.77 \pm 0.00^{\mathrm{a}}$ & $7.86 \pm 0.01^{\mathrm{a}}$ \\
\hline Tensile strength (MPa) & $34.05 \pm 1.23^{\mathrm{a}}$ & $27.84 \pm 0.54^{\mathrm{b}}$ & $23.95 \pm 0.69^{\mathrm{c}}$ \\
\hline Puncture strength (N) & $10.63 \pm 0.33^{\mathrm{b}}$ & $13.85 \pm 0.87^{\mathrm{a}}$ & $8.49 \pm 0.14^{\mathrm{c}}$ \\
\hline Elongation (\%) & $85.05 \pm 1.06^{\mathrm{c}}$ & $88.89 \pm 0.21^{\mathrm{b}}$ & $129.7 \pm 1.85^{\mathrm{a}}$ \\
\hline Oxygen permeability $\left(\mathrm{cm}^{3} / \mathrm{m}^{2} /\right.$ day $)$ & $49.0 \pm 0.02^{\mathrm{a}}$ & $3.37 \pm 0.22^{\mathrm{b}}$ & $0.65 \pm 0.05^{\mathrm{c}}$ \\
\hline $\operatorname{WVTR}\left(\mathrm{g} / \mathrm{m}^{2} /\right.$ day $)$ & $4303 \pm 25^{\mathrm{a}}$ & $4262 \pm 14^{\mathrm{a}}$ & $3805 \pm 10^{\mathrm{b}}$ \\
\hline Moisture in film (\%) & $8.25 \pm 0.01^{\mathrm{b}}$ & $8.21 \pm 0.00^{\mathrm{b}}$ & $9.05 \pm 0.00^{\mathrm{a}}$ \\
\hline Water solubility (\%) & $94.69 \pm 0.22^{\mathrm{a}}$ & $80.63 \pm 0.65^{\mathrm{c}}$ & $88.51 \pm 0.10^{\mathrm{b}}$ \\
\hline DPPH activity (\% scavenging) & $0.0 \pm 0.00^{\mathrm{c}}$ & $24.15 \pm 0.41^{\mathrm{a}}$ & $11.10 \pm 0.29^{b}$ \\
\hline \multicolumn{4}{|c|}{ Antibacterial effect (zone of inhibition in cm) } \\
\hline S. aureus & $0.0 \pm 0.00^{\mathrm{b}}$ & $2.6 \pm 0.11^{\mathrm{a}}$ & $2.5 \pm 0.05^{\mathrm{a}}$ \\
\hline B. cereus & $0.0 \pm 0.00^{\mathrm{b}}$ & $2.4 \pm 0.13^{\mathrm{a}}$ & $2.2 \pm 0.12^{\mathrm{a}}$ \\
\hline
\end{tabular}

"Values are given as mean \pm SD

*Different superscripts in the same row indicate significant ifferences $(p<0.05)$ 


\section{CONCLUSIONS}

The results of this study suggested that aqueous SWE had good antioxidant activity and also antimicrobial activity against $S$. aureus and B. cereus. Active packaging films were successfully developed by incorporating SWE to PVA. Interactions between PVA and polyphenolic compounds from SWE may play a major role on the modification of film properties. PVA-SWE films had excellent barrier properties against UV light and oxygen, while maintaining good mechanical properties. Thus, this study demonstrated that PVA films containing SWE could be used to prepare active food packaging films, and thus augment its applications in food industry. However, further studies with actual food products are required before using this film as an active food packaging material.

\section{REFERENCES}

Airanthi, M. W. A., Hosokawa, M., Miyashita, K. 2011. Comparative antioxidan activity of edible Japanese brown seaweeds. Journal of Food Science, 76, C104-C111. http://dx.doi.org/10.1111/j.1750-3841.2010.01915.x

Alekseyenko, T. V., Zhanayeva, S. Y., Venediktova, A. A., Zvyagintseva, T. N., Kuznetsova, T. A. 2007. Antitumor and antimetastatic activity of fucoidan, a sulfated polysaccharide isolated from the Okhotsk Sea Fucus evanescens brown alga. Bulletin of Experimental Biology and Medicine, 143, 730-732. http://dx.doi.org/10.1007/s10517-007-0226-4

Artan, M., Li, Y., Karadeniz, F., Lee, S. H., Kim, M. M., Kim, S. K. 2008. AntiHIV-1 activity of phloroglucinol derivative, 6,6'-bieckol, from Ecklonia cava. Bioorganic and Medicinal Chemistry Letters, 16, 7921-7926. http://dx.doi.org/10.1016/j.bmc.2008.07.078

ASTM D 882-891. 1991. Standard test methods for tensile properties of thin plastic sheeting. In Annual book of ASTM standards. Philadelphia, PA: American Society for Testing \& Materials.

Chapman, V. J. 1970. Seaweeds and their uses. London, Methuen, 2nd ed., 304.

Cox, S., Abu-Ghannam, N., Gupta, S. 2010. An assessment of the antioxidant and antimicrobial activity of six species of edible Irish seaweeds. International Food Research Journal, 17, 205-220.

Decker, E. A., Welch, B. 1990. Role of ferritin as lipid oxidation catalyst in muscle food. Journal of Agricultural Food Chemistry, 38, 674-677. http://dx.doi.org/10.1021/jf00093a019

Farvin, K. H. S., Jacobsen, C. 2013. Phenolic compounds and antioxidan activities of selected species of seaweeds from Danish coast. Food Chemistry 138, 1670-1681. http://dx.doi.org/10.1016/j.foodchem.2012.10.078

Ganesan P, Kumar C. S., Bhaskar N. 2008. Antioxidant properties of methanol extract and its solvent fractions obtained from selected Indian red seaweeds. $\begin{array}{llll}\text { Bioresource Technology, } & \text { 99, 2717-2723. }\end{array}$ http://dx.doi.org/10.1016/j.biortech.2007.07.005

Ghasemlou, M., Khodaiyan, F., Oromiehie, A. 2011. Physical, mechanical, barrier,and thermal properties of polyol-plasticized biodegradable edible film madefrom kefiran. Carbohydrate Polymers, 84, 477-483. http://dx.doi.org/10.1016/j.carbpol.2010.12.010

Gómez-Estaca, J., Giménez, B., Montero, P., Gómez-Guillén, M. C. 2009. Incorporation of antioxidant borage extract into edible films based on sole skin gelatin or a commercial fish gelatin. Journal of Food Engineering, 92, 78-85. http://dx.doi.org/10.1016/j.jfoodeng.2008.10.024

Gontard, N., Guilbert, S., Cuq, F. L. 1993. Water and glycerol as plasticizer affect mechanical and water vapour barrier properties of an edible wheat gluten film. Journal of Food Science, 58, 206-211. http://dx.doi.org/10.1111/j.1365-2621.1993.tb03246.x

Han, J. H., Floros, J. D. 1997. Casting antimicrobial packaging films and measuring their physical properties and antimicrobial activity. Journal of Plastic Film and Sheeting, 13, 287-298.

Ismail, A., Hong, T. S. 2002. Antioxidant activity of selected commercial seaweeds. Malaysian Journal of Nutrition, 8, 167-177.

Jin, Z., Wang, S., Wang, J., Zhao, M. X. 2012. Effects of plasticization conditions on the structures and properties of cellulose packaging films from ionic liquid [BMIM]Cl. Journal of Applied Polymer Science, 125, 704-709. http://dx.doi.org/10.1002/app.34975

Kim, D. O., Jeong, S. W., Lee, C. Y. 2003. Antioxidant capacity of phytochemicals from various cultivars of plums. Food Chemistry, 81, 321326.

Kumar, K. S., Ganesan, K., Subba Rao, P.V. 2008. Antioxidant potential of solvent extracts of Kappaphycus alvarezii (Doty) Doty - An edible seaweed. Food Chemistry, 107, 289-295.

Lalopua, V., Purnomo, H., Sukoso, Aulani'am .2011. Red seaweed (Kappaphycus alvarezii DOTY) from Mollucas island water as potential flavonoid resource of natural antioxidant. Livestock Research for Rural Development, 23

Liu, M., Hansen, P. E., Lin, X. 2011. Bromophenols in marine algae and their bioactivities. Marine Drugs, 9, 1273-1292.

Norajit, K., Kim, K. M., Ryu, G. H. 2010. Comparative studies on the characterization and antioxidant properties of biodegradable alginate films containing ginseng extract. Journal of Food Engineering, 98, 377-384.
Núñez-Flores, R., Giménez, B., Fernández-Martín, F., López-Caballero, M. E., Montero, M. P., Gómez-Guillén, M. C. 2012. Role of lignosulphonate in properties of fish gelatin films. Food Hydrocolloids, 27, 60-71.

Oyaizu, M. 1986. Studies on products of browning reaction: antioxidative activities of products of browning reaction prepared from glucosamine. Japanese Journal of Nutrition, 44, 307-315.

Rattaya, S., Benjakul, S., Prodpran, T. 2009. Properties of fish skin gelatin film incorporated with seaweed extract. Journal of Food Engineering, 95, 151-157.

Rhimou, B., Hassane, R., José, M., Nathalie, B. 2010. The antibacterial potential of the seaweeds (Rhodophyceae) of the Strait of Gibraltar and the Mediterranean coast of Morocco. African Journal of Biotechnology, 9, 63656372.

Rodrigueza, M. R. C., Montaño, M. N. E. 2007. Bioremediation potential of three carrageenophytes cultivated in tanks with seawater from fish farms. Journal of Applied Phycology, 19, 755-762.

Santoso, J. Y, Yoshie, T., Suzuki, T. 2002. The distribution and profile of nutritions and catechins of some Indonesian seaweed. Fisheries Science, 68 , 1647-1648.

Singleton, V. L., Rossi, J. A. 1965. Colorimetry of total phenolics with phosphomolybdic-phosphotungtic acid reagents. American Journal of Enology and Viticulture, 16, 144-158.

Siriwardhana, N., Lee, K. W., Jeon, Y. J., Kim, S. H., Haw, J. W. 2003. Antioxidant activity of Hizikia fusiformis on reactive oxygen species scavenging and lipid peroxidation inhibition. Food Science and Technology International, 9, 339-346. http://dx.doi.org/10.1177/1082013203039014

Sivarooban, T., Hettiarachchy, N. S., Johnson, M. G. 2008. Physical and antimicrobial properties of grape seed extract, nisin, and EDTA incorporated soy protein edible films. Food Research International, 41, 781-785.

Srinivasa, P. C., Ramesh, M. N., Tharanathan, R. N. 2007. Effect of plasticizers and fatty acids on mechanical and permeability characteristics of chitosan films. Food Hydrocolloids, 21, 1113-1122.

Stuchell, Y. M., Krochta, J. M. 1994. Enzymatic treatments and thermal effects on edible soy protein films. Journal of Food Science, 59, 1332-1337.

Velioglu, Y. S., Mazza, G., Gao, L., Oomah, B. D. 1998. Antioxidant activity and total phenolics in selected fruits, vegetables and grain products. Journal of Agricultural Food Chemistry, 46, 4113-4117.

Wangensteen, H., Samuelsen, A. B., Malterud, K. E. 2004. Antioxidant activity in extracts from coriander. Food Chemistry, 88, 293-297.

Yamaguchi, T., Takamura, H., Matoba, T., Terao, J. 1998. HPLC method for the evaluation of the free radical-scavenging activity of foods by using 1,1 diphenyl-2-picrylhydrazyl. Bioscience Biotechnology Biochemistry, 62, 12011204.

Zhou, K., Yu, L. 2004. Effects of extraction solvent on wheat bran antioxidant activity estimation. LWT - Food Science and Technology, 37, 717-721. 